\title{
An empirical method for particle damping design
}

\author{
Zhi Wei Xu ${ }^{\mathrm{a}}$, K.W. Chan ${ }^{\mathrm{b}}$ and W.H. Liao ${ }^{\mathrm{b}, *}$ \\ ${ }^{a}$ The Aeronautical Science Key Laboratory for Smart Materials and Structures, Nanjing University of Aeronautics \\ and Astronautics, Nanjing, China \\ ${ }^{\mathrm{b}}$ Department of Automation and Computer-Aided Engineering, The Chinese University of Hong Kong, Hong Kong, \\ China
}

Received May 2003

Accepted May 2004

\begin{abstract}
Particle damping is an effective vibration suppression method. The purpose of this paper is to develop an empirical method for particle damping design based on extensive experiments on three structural objects - steel beam, bond arm and bond head stand. The relationships among several key parameters of structure/particles are obtained. Then the procedures with the use of particle damping are proposed to provide guidelines for practical applications. It is believed that the results presented in this paper would be helpful to effectively implement the particle damping for various structural systems for the purpose of vibration suppression.
\end{abstract}

Keywords: Particle damping, vibration suppression

\section{Introduction}

Particle damping is one of the passive vibration suppression methods and the damping is achieved with granular particles embedded within small holes in a vibrating structure [1,2]. Particles absorb kinetic energies and change them into heat energies through collisions and frictions among particles and the walls of the structure. The method has been shown to be effective and simple and can suppress broad frequency vibration for various applications [3,4]. In recent years, particle damping techniques have been further investigated [5-7], but many factors still need to be considered while applying the particles for obtaining significant damping, such as particle size, packing ratio, hole size, position, and so on. Based on extensive experiments on three structural objects - beam, bond arm and bond head stand, the objective of this paper is to provide design guidelines for utilizing particle damping and facilitate the application of particle damping for effective vibration suppression.

\section{Experiments on beam, bond arm and bond head stand}

Three structural objects performed in the experiments are shown in Fig. 1 The size of the steel beam is $500 \times$ $60 \times 12 \mathrm{~mm}$ and vertically oriented holes with $6 \mathrm{~mm}$ diameter and $10 \mathrm{~mm}$ depth have been drilled on the $300 \mathrm{~mm}$ length part of the beam. Bond head stand and bond arm shown in Fig. 1 are two important parts in the ultra-fine pitch electronics packaging machines that vibrations need to be suppressed during operations. The size of the holes in the bond head stand is $5 \mathrm{~mm}$ diameter. Due to the thin structure of the bond arm, several particle enclosures

\footnotetext{
*Corresponding author. E-mail: whliao@cuhk.edu.hk.
} 


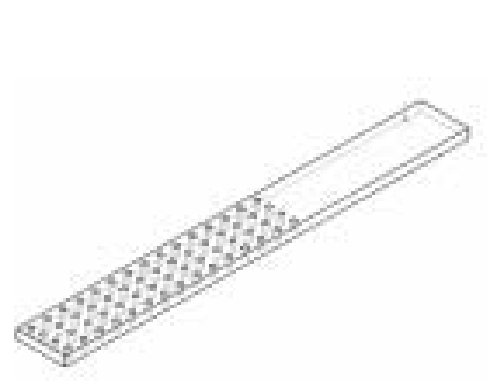

A. Beam

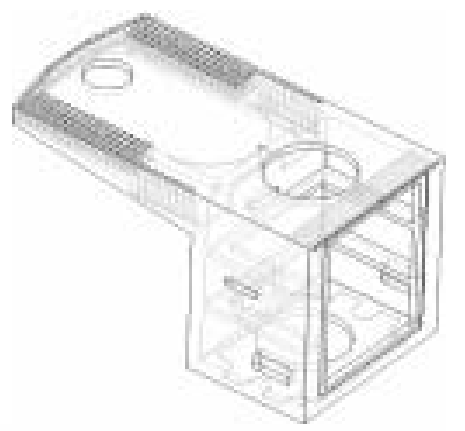

B. Bond head stand

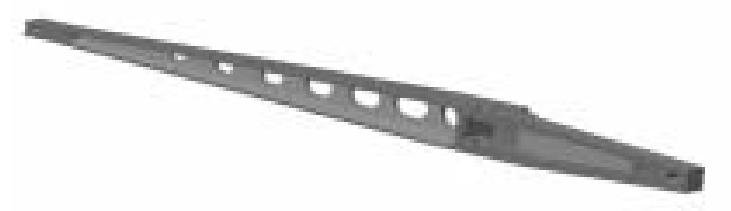

C. Bond arm

Fig. 1. Three structural objects.

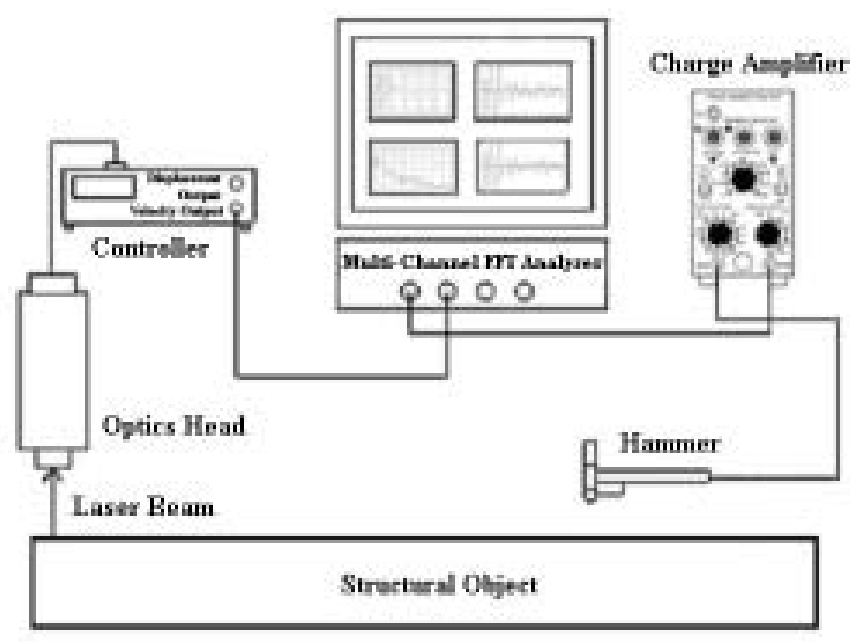

Fig. 2. Experimental setup.

with two different chambers are developed. The overall dimension is $20 \times 6 \times 6 \mathrm{~mm}$ with $1.0 \mathrm{~mm}$ in thickness. Each enclosure weighs around 0.42 gram. It can be stuck on the head of the bond arm with a special wax. The experimental setup is shown in Fig. 2. For the steel beam test, acceleration is obtained from the response at the tip of the cantilever beam, $300 \mathrm{~mm}$ from the fixed end, driven by the exciting force at $35 \mathrm{~mm}$ from the fixed end as shown in Fig. 3. White noise random signal generated from multi-channel analysis system (Br üel \& Kjær 3550) is applied to a vibration shaker (Brüel \& Kjær 4810) for excitation. During the experiments, extensive tests are carried out under different conditions by varying packing ratio, particle diameter and frequency, etc. After analyzing all experimental data, the relationships among frequency, packing ratio, particle diameter and damping ratio are obtained and shown in the following sections. 


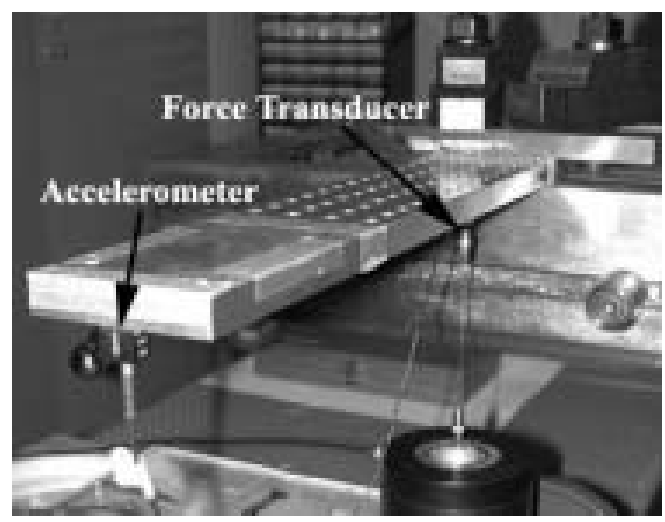

Fig. 3. Photo of beam test setup.

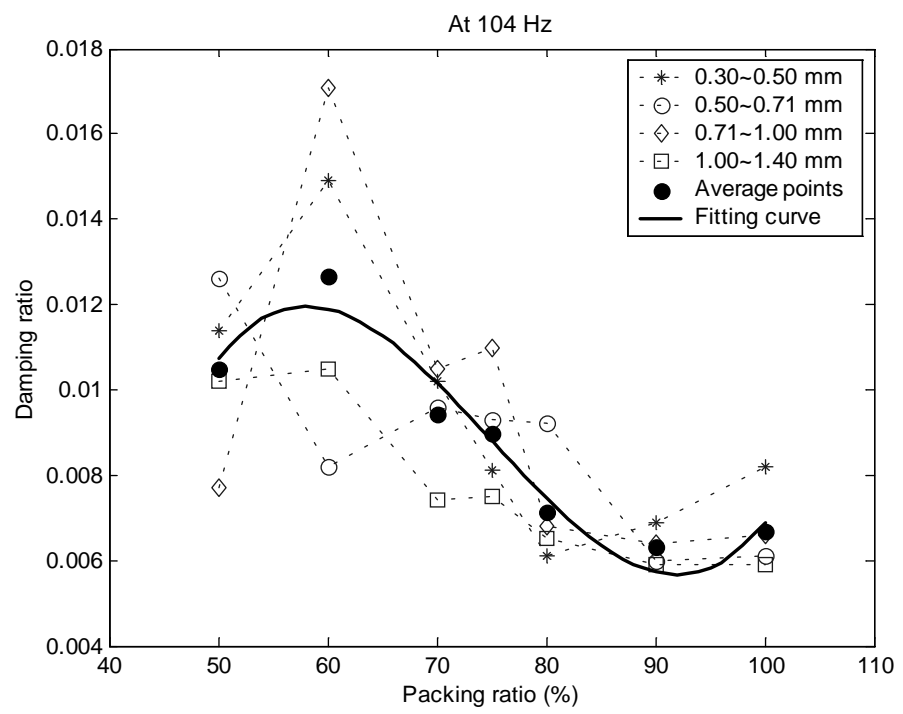

Fig. 4. Damping ratio vs. packing ratio for different particle diameters at $104 \mathrm{~Hz}$.

\section{Relationship between frequency and packing ratio}

The packing ratio of particles is one of the key factors that affect the effectiveness of vibration suppression using particle damping technique. Beam experiments under various conditions are performed. In the beam experiments, packing ratios of particles are $50 \%, 60 \%, 70 \%, 75 \%, 80 \%, 90 \%$, and $100 \%$ respectively. The packing ratio is defined as the ratio of the amount of granules filled in a hole to the total amount a hole can be filled. Under one specific packing ratio, particles with four ranges of diameters, $0.3 \sim 0.5 \mathrm{~mm}, 0.5 \sim 0.71 \mathrm{~mm}, 0.71 \sim 1.0 \mathrm{~mm}$ and $1.0 \sim$ $1.4 \mathrm{~mm}$, are used. The damping ratios for the same frequency are plotted in a figure. Figures $4-8$ show the results of damping ratios with respect to packing ratios for different frequencies. In order to explore the characteristics for a particular frequency, average values among different sizes of particles and the fitting curves of the average points are also shown. It can be seen from Fig. 4 that $60 \%$ is the packing ratio to have the highest damping when the frequency is $104 \mathrm{~Hz}$. When the packing ratio is larger than $60 \%$, the damping decreases with the increase of packing ratio until more than $90 \%$. Observing Fig. 5 for $640 \mathrm{~Hz}$, the fitting curve of the average points is almost a straight line at similar levels. That means the damping ratio is not sensitive to the packing ratio. Packing ratio $75 \%$ could be selected, where the average damping ratio is the biggest among all shown packing ratios. For higher frequencies at 1775 and $3380 \mathrm{~Hz}$, the average damping ratio increases with the increase of packing ratio as shown in Figs 6 


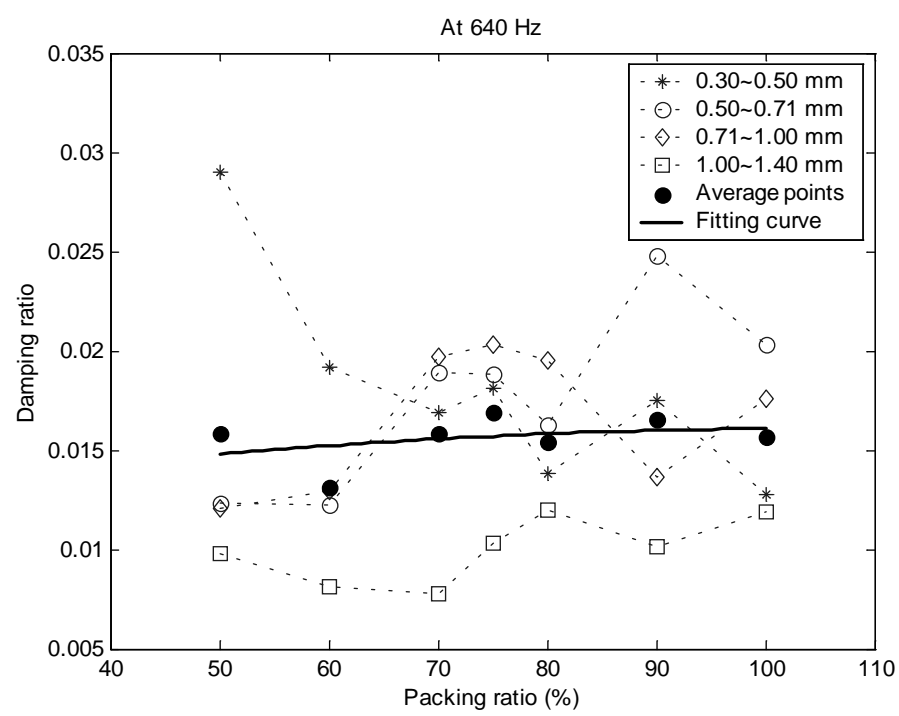

Fig. 5. Damping ratio vs. packing ratio for different particle diameters at $640 \mathrm{~Hz}$.

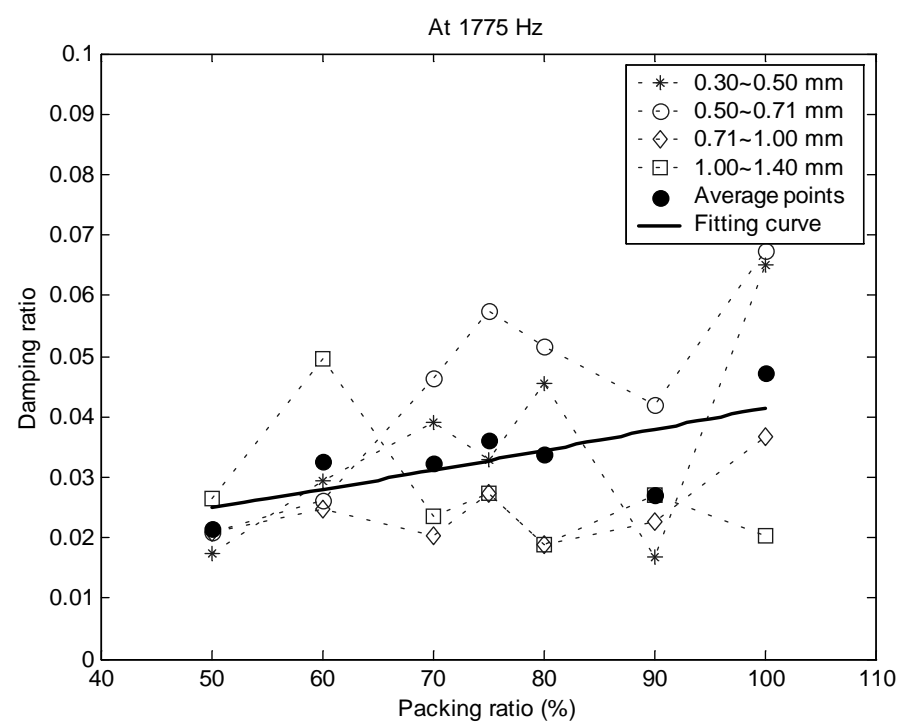

Fig. 6. Damping ratio vs. packing ratio for different particle diameters at $1775 \mathrm{~Hz}$.

and 7. Therefore, $100 \%$ packing ratio is considered as the best one for these frequencies. Similarly, as shown in Fig. 8, 85\% is the best packing ratio for the frequency $5440 \mathrm{~Hz}$. After obtaining the best packing ratios for those five different frequencies, the relationship between the frequency and packing ratio can then be plotted in Fig. 9, where the fitting curve with a polynomial function is also shown. With those results shown in Fig. 9 the packing ratio of particles can be initially decided according to the main frequency of a structure. This may not be the best packing ratio for the highest damping, but it would be a better one as the rule of thumb. Based on that, it can be found out that vibration suppression of the structure with lower packing ratio is effective at low frequency range as compared to higher frequencies. Furthermore, the trend may not depend on the types of structures. Various structures could have similar tendency; even the actual best packing ratio for different structures with corresponding frequencies could be different. Therefore, experiments for other structures besides beams should also be performed to verify if the curve in Fig. 9 could be applied for different kinds of structures. 


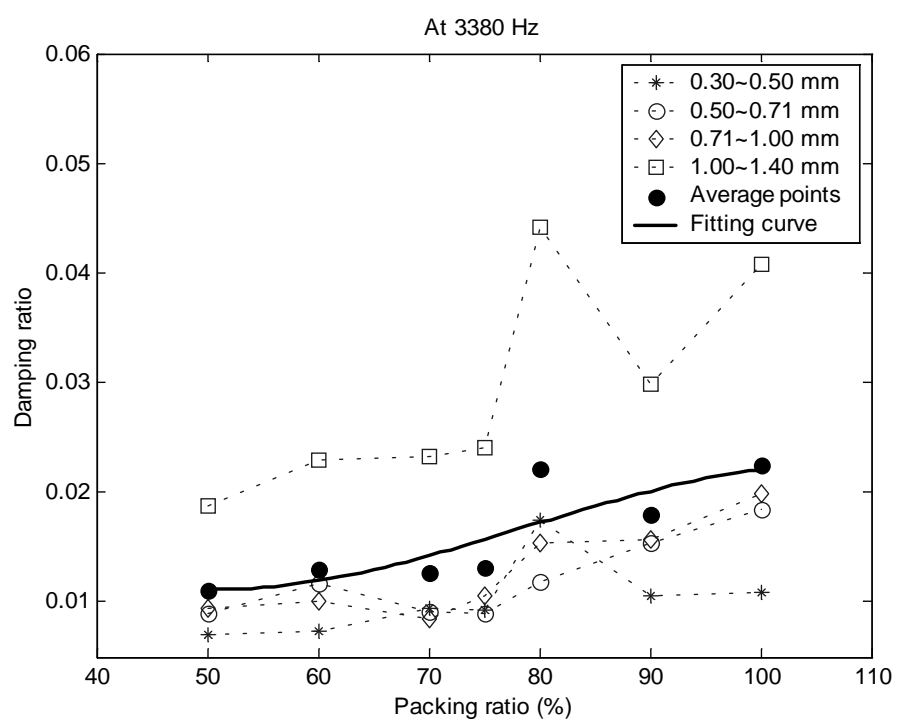

Fig. 7. Damping ratio vs. packing ratio for different particle diameters at $3380 \mathrm{~Hz}$.

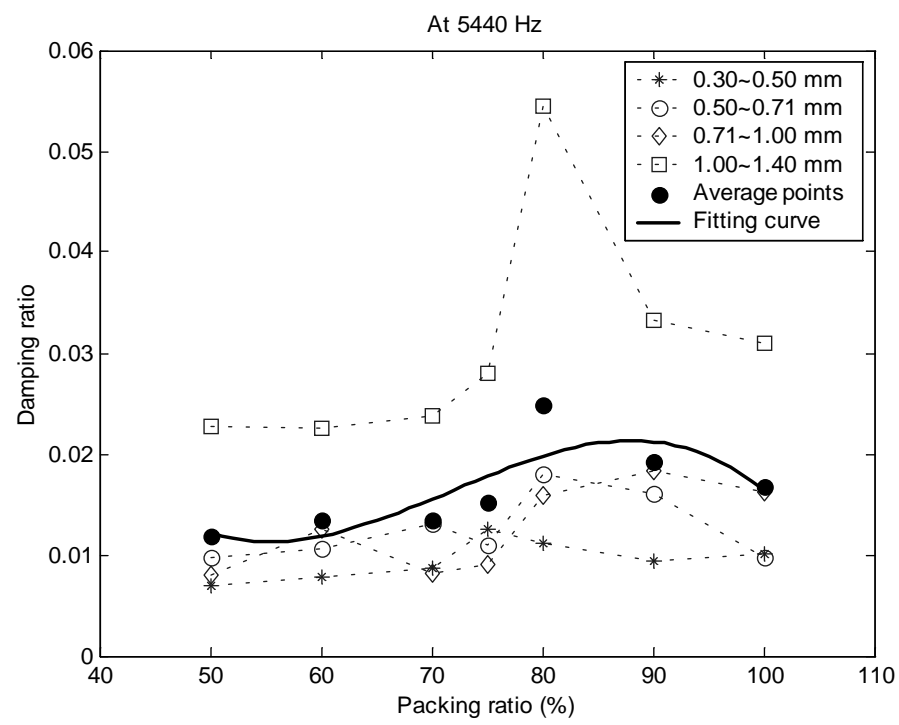

Fig. 8. Damping ratio vs. packing ratio for different particle diameters at $5440 \mathrm{~Hz}$.

\section{Relationship between particle diameter and damping ratio}

Particle diameter is also an important factor that affects vibration suppression performance with the use of particles. Based on the completed experimental data for the beam, the relationship between particle diameter and damping ratio can be obtained. First of all, the experimental results are plotted in Figs. 10-14, with respect to their frequencies. It is shown that, for the same frequency, most damping ratios versus particle diameter have the similar tendency for different packing ratios. In Fig. 10 for the frequency at $104 \mathrm{~Hz}$, the variation of damping ratio with particle diameter is small. As shown in Fig. 11 for $640 \mathrm{~Hz}$, the damping ratios when the particle diameter is 0.6 or $0.85 \mathrm{~mm}$ are bigger than that when the diameter is $1.2 \mathrm{~mm}$. For high frequencies at 3380 and $5440 \mathrm{~Hz}$, it can be seen from Figs. 13 and 14 that the damping ratios increase with the increase of the particle diameter, while Fig. 12 for $1775 \mathrm{~Hz}$ shows the hybrid trend between lower and higher frequencies. Then, in order to have a clear observation on the tendency, for the same 
Table 1

Average hitting forces for the bond head stand with small and big hammers

\begin{tabular}{lccc}
\hline & $\begin{array}{c}\text { Hitting force at } \\
\text { point } \mathrm{A}(\mathrm{N})\end{array}$ & $\begin{array}{c}\text { Hitting force at } \\
\text { point B }(\mathrm{N})\end{array}$ & $\begin{array}{c}\text { Hitting force at } \\
\text { point } \mathrm{C}(\mathrm{N})\end{array}$ \\
\hline Small hammer & 98.9 & 101.2 & 75.2 \\
Big hammer & 3431 & 3347 & 3337 \\
\hline
\end{tabular}

Table 2

Average force on the beam and the bond arm

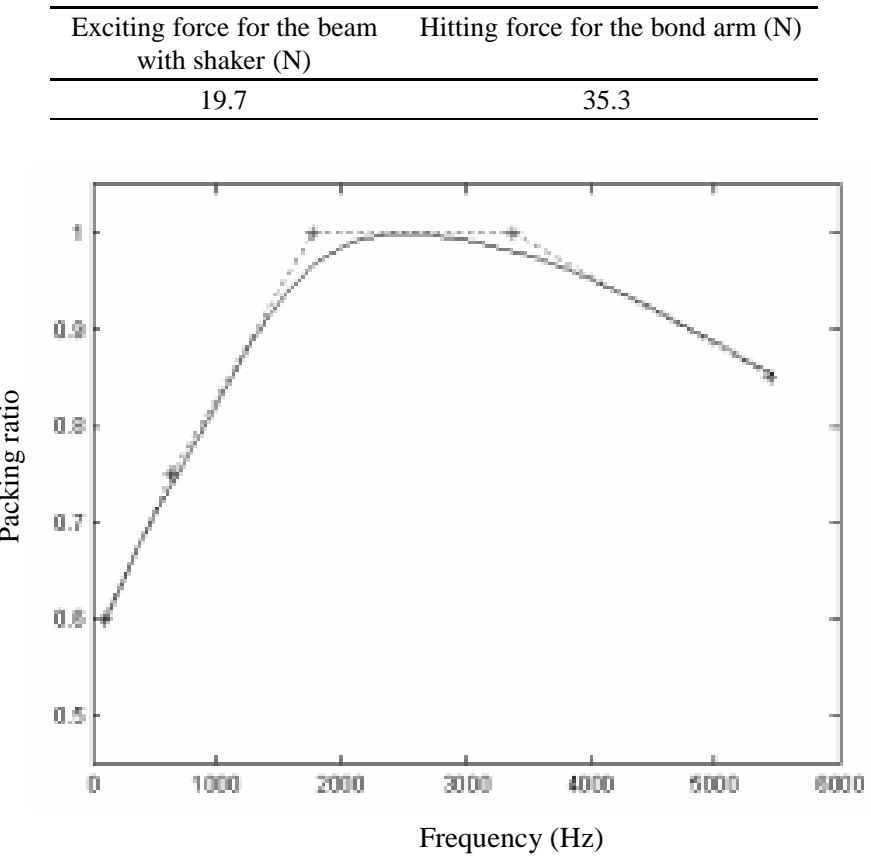

Fig. 9. The relationship between packing ratio and frequency.

particle diameter, the damping ratios with different packing ratios are averaged. The averaged damping ratios are shown in Figs. 10-14 with the bold dots. From Fig. 10, the largest averaged damping ratio is about 0.009 when the particle diameter is $0.4 \mathrm{~mm}$. So $0.4 \mathrm{~mm}$ is the selected particle diameter of particles for high damping performance when the frequency is $104 \mathrm{~Hz}$. Similarly, $0.6 \mathrm{~mm}, 0.6 \mathrm{~mm}$ and $1.2 \mathrm{~mm}$ are the selected particle diameters when the frequencies are 640, 1775 and $3380 \mathrm{~Hz}$ respectively. At $5440 \mathrm{~Hz}, 1.2 \mathrm{~mm}$ is also the choice for the particle diameter. Since $1.2 \mathrm{~mm}$ is the biggest particle diameter in the performed experiments and it is already the selected diameter when the frequency is $3380 \mathrm{~Hz}$, the highest used frequency will be limited to $3380 \mathrm{~Hz}$ here. Finally, the selected particle diameters versus frequencies are plotted in Fig. 15 and the fitted curve with a polynomial function is also shown.

The particle diameter can be decided with the use of Fig. 15. It should be noted that the ranges of particle diameter and frequency are limited to our performed experiments. As a result, the relationship between frequency and particle diameter is just a reference in the design process, for the similar ranges of frequencies and particle sizes. In addition, the results discussed here reflect the tendency of particles used for the beam structure. For other structures, similar trend could be found; but it is not sure if the particle diameter obtained from Fig. 15 will be the best one. More experiments are needed to verify if this curve can be applied to other structures.

\section{Effective frequency with particle damping}

From the experiments, it was also found that particle damping is effective when the acceleration of the structure is high enough. The collisions and frictions of particle-to-particle and particle-to-wall are the main mechanisms 


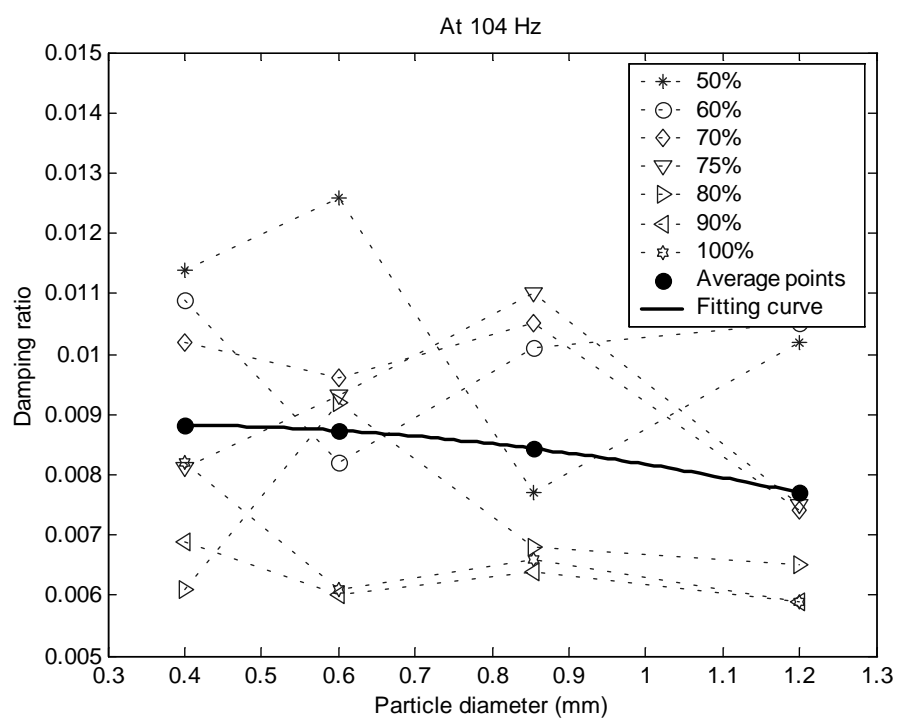

Fig. 10. Damping ratio vs. particle diameter for different packing ratios at $104 \mathrm{~Hz}$.

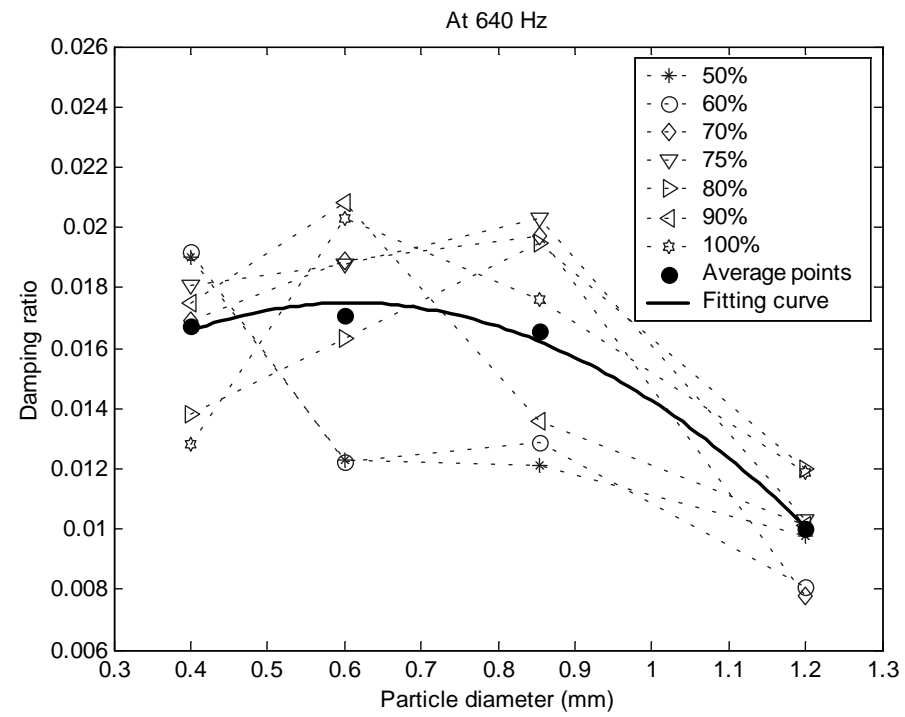

Fig. 11. Damping ratio vs. particle diameter for different packing ratios at $640 \mathrm{~Hz}$.

for vibration suppression. When the accelerations of particles reach a certain level, the collisions and frictions are significant and then the vibration energy of the structure is dissipated by the particles. However, it is still unknown what the acceleration value is. The following parts are what we try to find the value based on the testing data obtained.

\subsection{Displacements of bond arm, beam, and bond head stand}

In the tests performed, the results have been emphasized on the frequency response functions. As a result, the displacements of these structures were not directly measured. Furthermore, the displacements under some conditions are so small that they may not be measured with the existing equipment. Therefore, the displacements are obtained in another way. 
Table 3

Calculated displacements of the bond head stand, bond arm, and beam

\begin{tabular}{|c|c|c|c|c|}
\hline & Excitation condition & $\begin{array}{l}\text { Calculated average displ- } \\
\text { acement per unit force (m) }\end{array}$ & $\begin{array}{l}\text { Calculated maximum displ- } \\
\text { acement per unit force }(\mathrm{m})\end{array}$ & $\begin{array}{l}\text { Calculated largest displ- } \\
\text { acement under experimental } \\
\text { condition }(\mu \mathrm{m})\end{array}$ \\
\hline \multirow[t]{6}{*}{ Bond head stand } & Small hammer A & $0.281 \mathrm{E}-07$ & $0.393 \mathrm{E}-07$ & 3.88 \\
\hline & Small hammer B & $0.274 \mathrm{E}-07$ & $0.408 \mathrm{E}-07$ & 4.12 \\
\hline & Small hammer $\mathrm{C}$ & $0.496 \mathrm{E}-07$ & $0.761 \mathrm{E}-07$ & 5.72 \\
\hline & Big hammer $\mathrm{A}$ & $0.229 \mathrm{E}-07$ & $0.295 \mathrm{E}-07$ & 101.3 \\
\hline & Big hammer B & $0.238 \mathrm{E}-07$ & $0.312 \mathrm{E}-07$ & 104.3 \\
\hline & Big hammer $\mathrm{C}$ & $0.496 \mathrm{E}-07$ & $0.761 \mathrm{E}-07$ & 254.0 \\
\hline Bond arm & & $0.901 \mathrm{E}-06$ & $0.927 \mathrm{E}-06$ & 32.7 \\
\hline Beam & & $0.396 \mathrm{E}-06$ & $0.396 \mathrm{E}-06$ & 7.79 \\
\hline
\end{tabular}

Table 4

Accelerations of the effective frequencies

\begin{tabular}{lcccccc}
\hline & $\begin{array}{c}\text { Excitation } \\
\text { condition }\end{array}$ & $\begin{array}{c}\text { Largest } \\
\text { displacement } \\
(\mu \mathrm{m})\end{array}$ & $\begin{array}{c}\text { Effective } \\
\text { frequency } \\
(\mathrm{Hz})\end{array}$ & $\begin{array}{c}X_{0}^{*} f^{2} \\
\left(\mathrm{~m} / \mathrm{s}^{2}\right)\end{array}$ & $\begin{array}{c}\text { Modal frequency } \\
\text { below effective } \\
\text { frequency }(\mathrm{Hz})\end{array}$ & $\begin{array}{c}X_{0}^{*} f^{2} \\
\left(\mathrm{~m} / \mathrm{s}^{2}\right)\end{array}$ \\
\hline Bond head stand & Small force A & 3.88 & 1220 & 5.77 & 500 & 0.97 \\
& Small force B & 4.12 & 1220 & 6.13 & 500 & 1.03 \\
& Small force C & 5.72 & 1220 & 8.51 & 500 & 1.43 \\
& Big force A & 101.3 & 239 & 5.79 & 125 & 1.58 \\
Bond arm & Big force B & 104.3 & 239 & 5.96 & 125 & 1.63 \\
Beam & Big force C & 254.0 & 125 & 3.97 & 107 & 2.91 \\
\hline
\end{tabular}

In the experiments, we can obtain the maximum exciting force for each case from the time history signal under broadband frequency excitation. Then the average hitting or exciting force for each structure, shown in Tables 1 and 2, can be obtained. The measurement points on the bond head stand are shown in Fig. 16. Using the instrumented impact hammer (Type 8202 Brüel \& Kjær, named "small hammer"), high frequency modes of the head stand can be excited, However, since lower frequency $(<500 \mathrm{~Hz})$ structural response is insignificant under the excitation of the small hammer, a modally tuned hammer (model 086C20 PCB Piezotronics, named "big hammer") is used here to test heavier structures for low to medium frequencies. Based on the average maximum exciting forces, the displacements of each structure can be calculated by Finite Element Analysis (FEA) when subjected to broadband frequency exciting forces. When the exciting force is $1 \mathrm{~N}$, the structural displacements can be calculated. Then the total structural displacement can be obtained by multiplying the 1-N displacement by the exciting force from the experiments. The calculated displacement results under 1-N exciting force are shown in Figs. 17-20.

The displacements where particles are located are of major concern. Thus several displacements of each object under various conditions are extracted from the calculation results at measured points where are in the area of particles added. Then the average and maximum displacements with 1-N exciting force are obtained, as shown in Table 3. The largest displacements under experimental conditions can be obtained by the multiplication of average experimental acting forces and the calculated maximum displacements excited by $1-\mathrm{N}$ force. The results are also shown in Table 3.

\subsection{Effective frequency while particles applied}

Effective frequency is defined as a frequency value that particle damping will be effective when the frequency is greater than the value, while it would be ineffective the other way. Based on the experimental results under broadband frequency excitations, the effective frequencies of the beam, bond arm, and bond head stand are given in Table 4. Due to some experimental errors, such as the variation of the boundary condition, the inconsistence of the exciting point and so on, the particle damping could be effective below the effective frequency from a frequency response function, but particles could be found to be ineffective in other response functions. As a result, the effective frequency, which the particle damping is effective in all tested frequency response functions, is selected. 


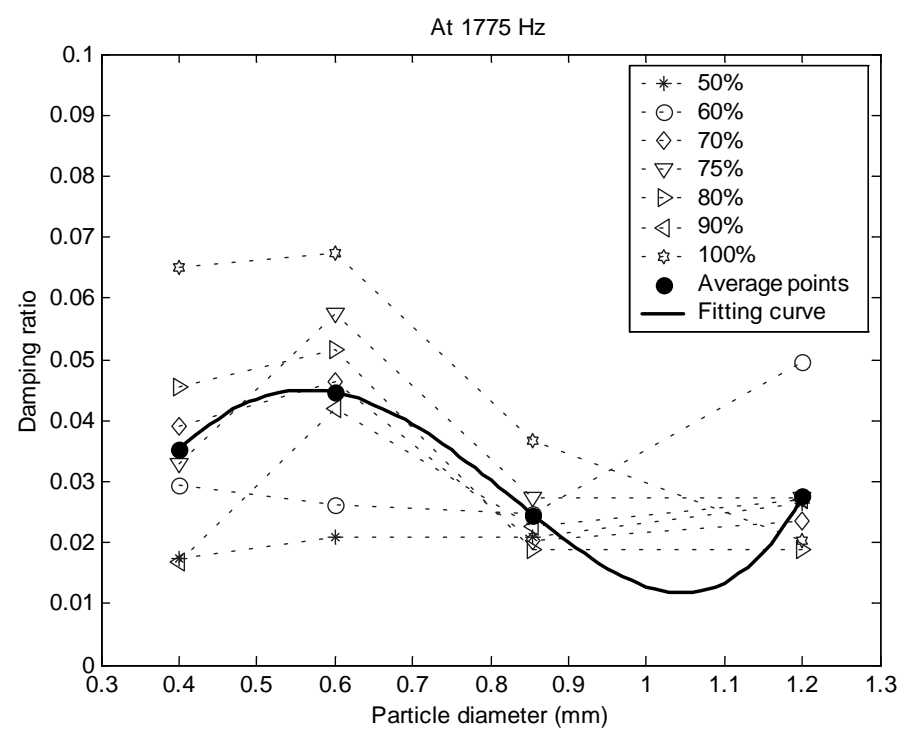

Fig. 12. Damping ratio vs. particle diameter for different packing ratios at $1775 \mathrm{~Hz}$.

Table 5

Acceleration at the frequency of interest under the bonding process

\begin{tabular}{cccc}
\hline & Largest displacement $X_{0}(\mu \mathrm{m})$ & Frequency $f(\mathrm{~Hz})$ & $X_{0}^{*} f^{2}\left(\mathrm{~m} / \mathrm{s}^{2}\right)$ \\
\hline Bond head stand & 40 & 245 & 2.40 \\
\hline
\end{tabular}

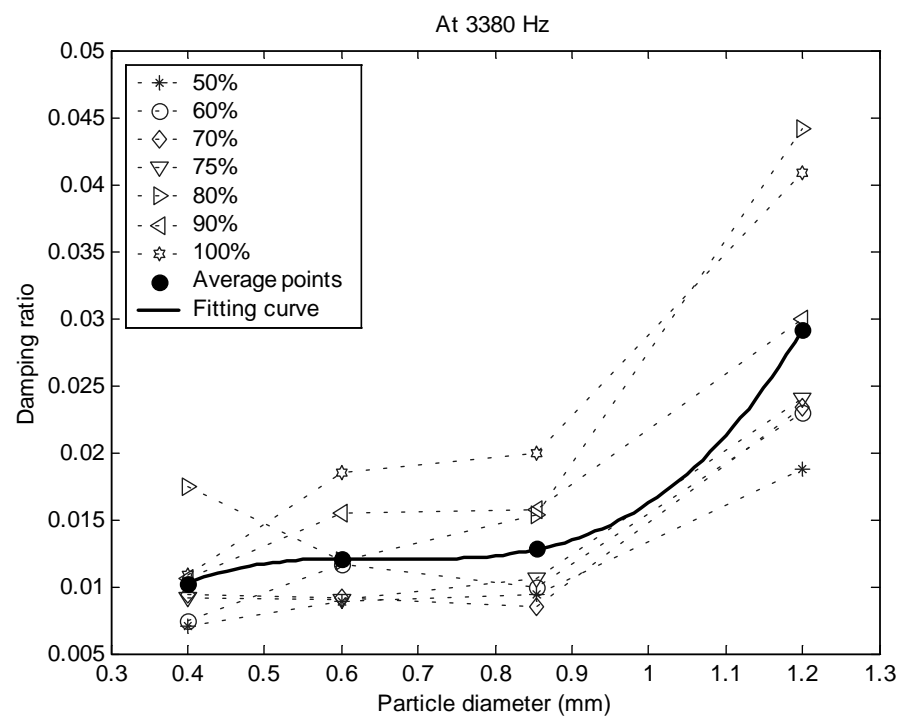

Fig. 13. Damping ratio vs. particle diameter for different packing ratios at $3380 \mathrm{~Hz}$.

Based on the calculated displacement and the effective frequency, we can calculate the acceleration for effective particle damping. At the same time, we can also calculate the acceleration for the maximum modal frequency below the effective frequency if available. The calculated accelerations are shown in Table 4. It should be noted that boundary conditions are ideally specified during the FEA process. However, the same boundary conditions might not be perfectly fixed in the experimental tests. Thus the actual displacements could be greater than the calculated ones. Then the actual accelerations of the effective frequencies could also be greater than the values shown in Table 4 . 


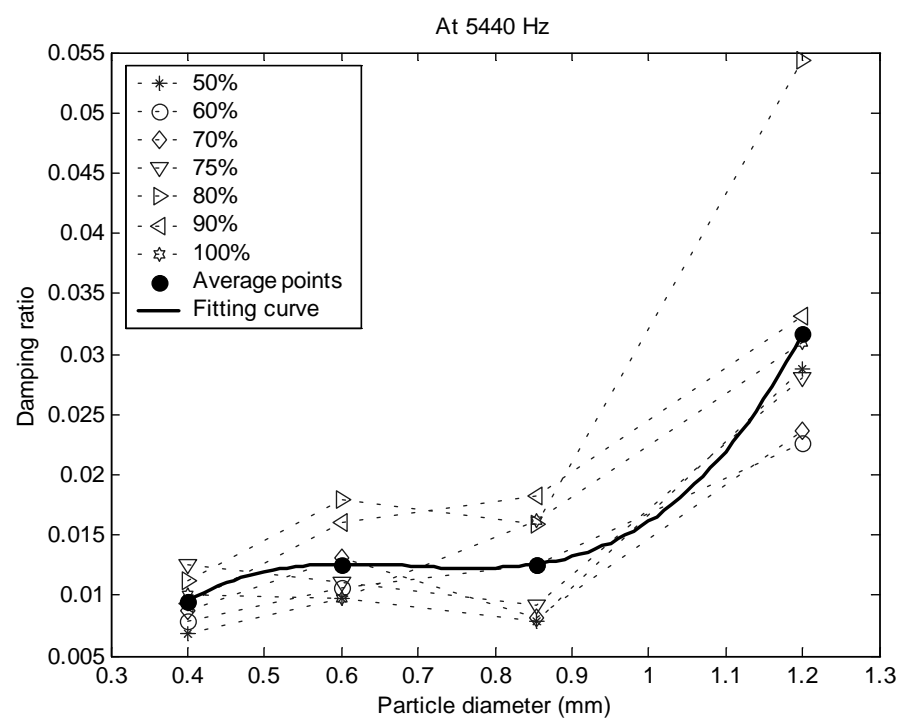

Fig. 14. Damping ratio vs. particle diameter for different packing ratios at $5440 \mathrm{~Hz}$.

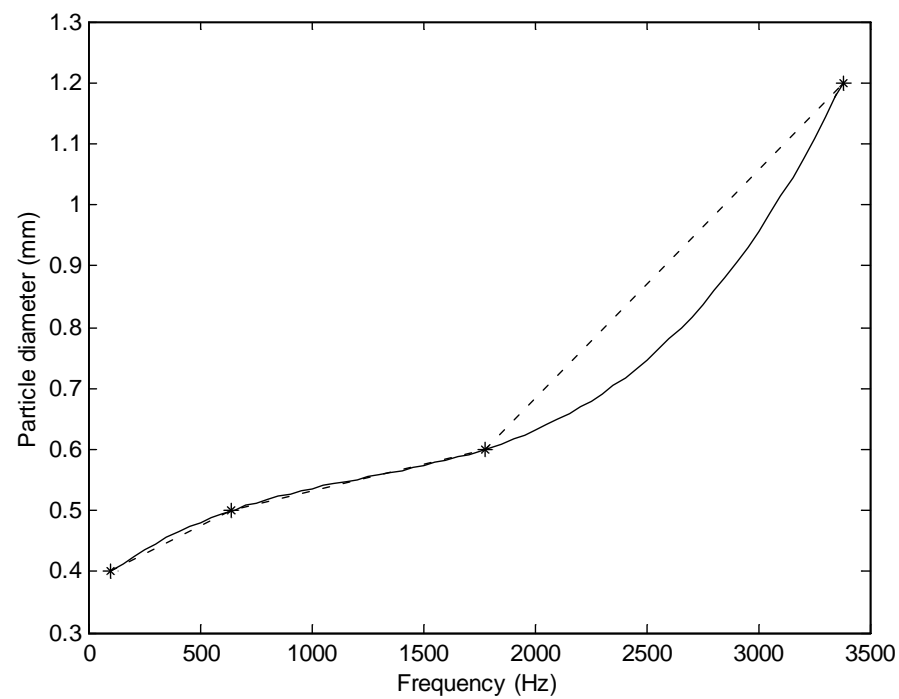

Fig. 15. The relationship between particle diameter and frequency.

Experiments of the bond head stand under bonding processes have been performed on site. The frequency of concern is $245 \mathrm{~Hz}$, however, the particle damping has been found to be ineffective at this frequency. The displacements during the bonding processes were measured. The maximum displacement is about $40 \mu \mathrm{m}$. Thus the acceleration at $245 \mathrm{~Hz}$ is shown in Table 5 .

From Tables 4 and 5, it can be found that all the accelerations for effective frequencies are bigger than $3.29 \mathrm{~m} / \mathrm{s}^{2}$. When acceleration is 2.40 or $2.91 \mathrm{~m} / \mathrm{s}^{2}$, the particle damping is ineffective. Therefore, it can be concluded that the particle damping will be effective when the acceleration is greater than one specific value, regardless of structures. From the above analysis, this specific constant for $X_{0}^{*} f^{2}$ can be chosen to be $3.5 \mathrm{~m} / \mathrm{s}^{2}$. This means that the particle damping will be effective if the value of $X_{0}^{*} f^{2}$ for a structure is greater than $3.5 \mathrm{~m} / \mathrm{s}^{2}$, and the particle damping would be insignificant when $X_{0}^{*} f^{2}$ is smaller than $3.5 \mathrm{~m} / \mathrm{s}^{2}$. Based on the displacements and the values of $X_{0}^{*} f^{2}$, we can predict the effective frequencies of the bond head stand, bond arm and beam under various conditions. The results are shown in Table 6 . It should be noted that $3.5 \mathrm{~m} / \mathrm{s}^{2}$ is not an exact value to be used because the existing 


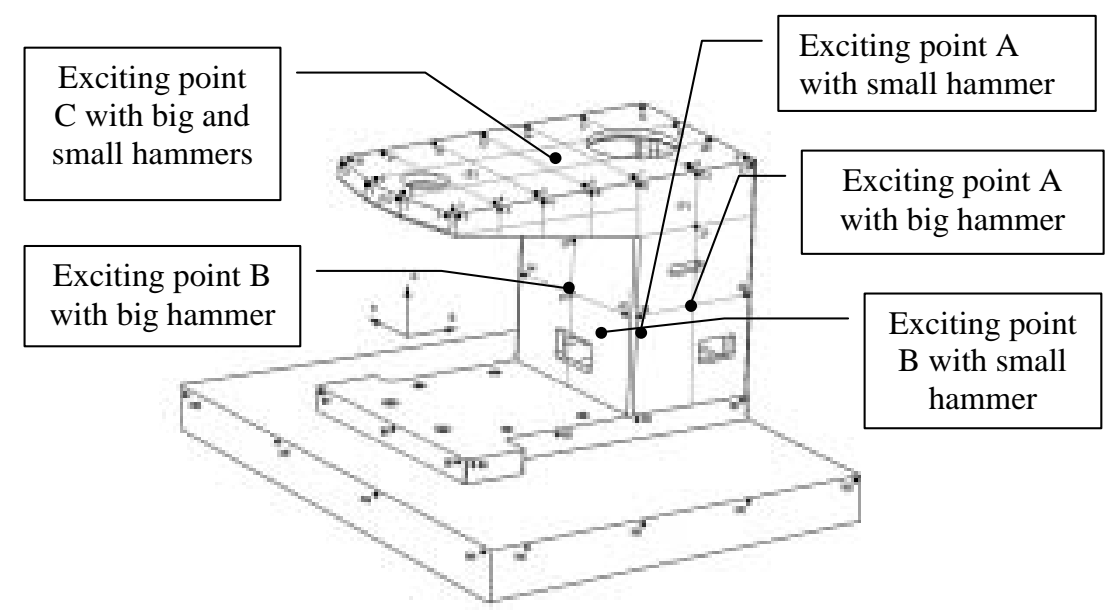

Fig. 16. Measuring points in $x-, y$-, and $z$-direction on the bond head stand and base.

Table 6

Predicted effective frequencies

\begin{tabular}{llcc}
\hline & Excitation condition & Biggest displacement $(\mu \mathrm{m})$ & Predicted effective frequency $(\mathrm{Hz})$ \\
\hline Bond head stand & Small force A & 3.88 & 949.8 \\
& Small force B & 4.12 & 921.7 \\
& Small force C & 5.72 & 782.2 \\
& Big force A & 101.3 & 184.1 \\
& Big force B & 104.3 & 182.5 \\
& Big force C & 254.0 & 117.1 \\
Bond arm & & 32.7 & 331.8 \\
Beam & & 7.79 & 670.3 \\
Bond head & Under bonding & 40 & 295.8 \\
stand & process & & \\
\hline
\end{tabular}

experimental data are limited. In fact, more experiments could be done to have more accurate results to verify the proposed guideline.

\section{Procedures with the use of particle damping}

Based on experiments, calculations and analyses, the procedures for applying particles to structures are summed up. For the purpose of discussion, the bond arm and/or bond head stand are selected as the example structures. The design procedures for applying particles to the bond arm are described in details as follows.

\section{Step 1: Modal analysis via FEA}

FEA is a useful tool for obtaining the mode shapes and frequencies of a structure. To get accurate results, material properties, such as mass density, modulus of elasticity and Poisson's ratio, have to be specified for the structural model, while element type and number need to be decided cautiously for the analysis. Due to the variation of boundary conditions and other aspects between analyses and experiments, the analytical resonance frequencies could be different from those from experiments. However, the mode shapes of the structure would be accurately obtained either from analyses or experiments. The mode shapes and natural frequencies of the bond arm are shown in Fig. 21. It has been found that the differences of frequencies between FEA and experimental results are within $8 \%$.

Step 2: Measurement of the structure under operating condition and verification of the feasibility for effective particle damping 


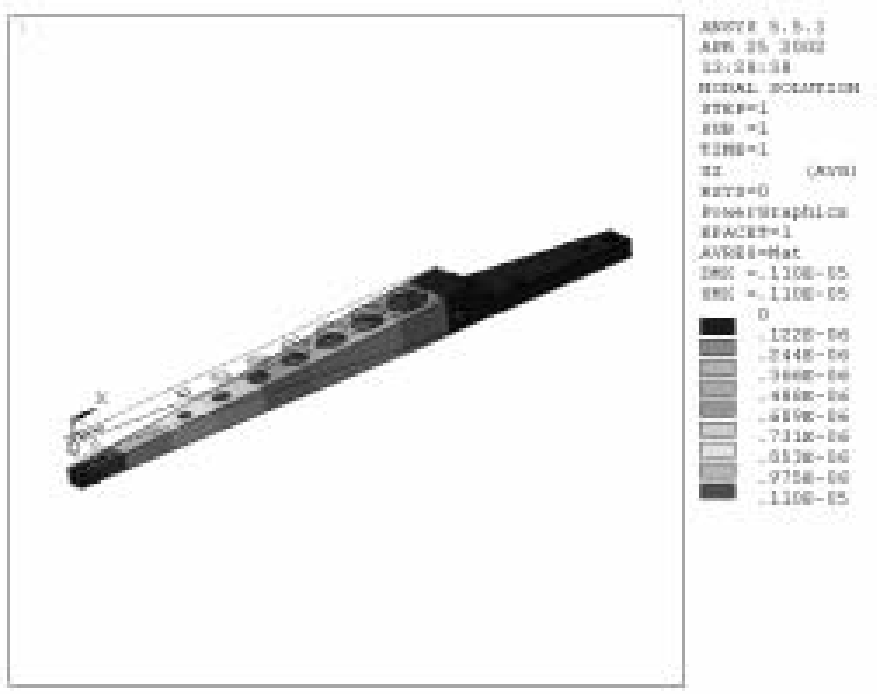

Fig. 17. Bond arm displacement under $1 \mathrm{~N}$ hitting force.

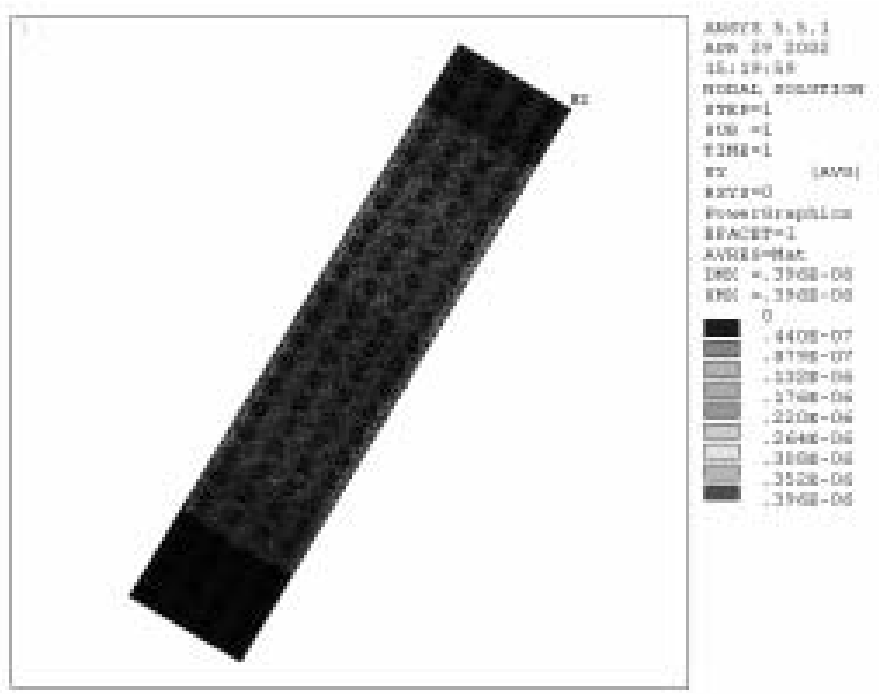

Fig. 18. Beam displacement under $1 \mathrm{~N}$ exciting force.

Measurement points need to be chosen based on the results in step 1. In order to avoid missing key resonance frequencies, the measurement points must be selected in the area where the nodes of structural modes do not exist. For example, we can find the nodes of the 3rd and 6th mode shapes from Fig. 21. The 4th and 5th modes are torsional modes. If the sensor is placed on the middle of the arm, these two modes cannot be measured. But if the torsional modes are not excited under the operating condition, then they can be ignored by putting the sensor on the middle of the arm. There is no node for the 1 st and 2nd modes, so they can be measured. In principle, all points except nodes can be selected as the measurement points, but in fact the points with high displacement are recommended. From the above discussion, the measurement points can then be chosen, as shown in Fig. 22. Here, at least two measurement points for the bond arm are needed. For a large structure, such as bond head stand, the number of measurement points should be increased due to the uncertainties on the points and directions for higher amplitudes. Also, the constraints for the measured points under realistic operating conditions should be considered. 


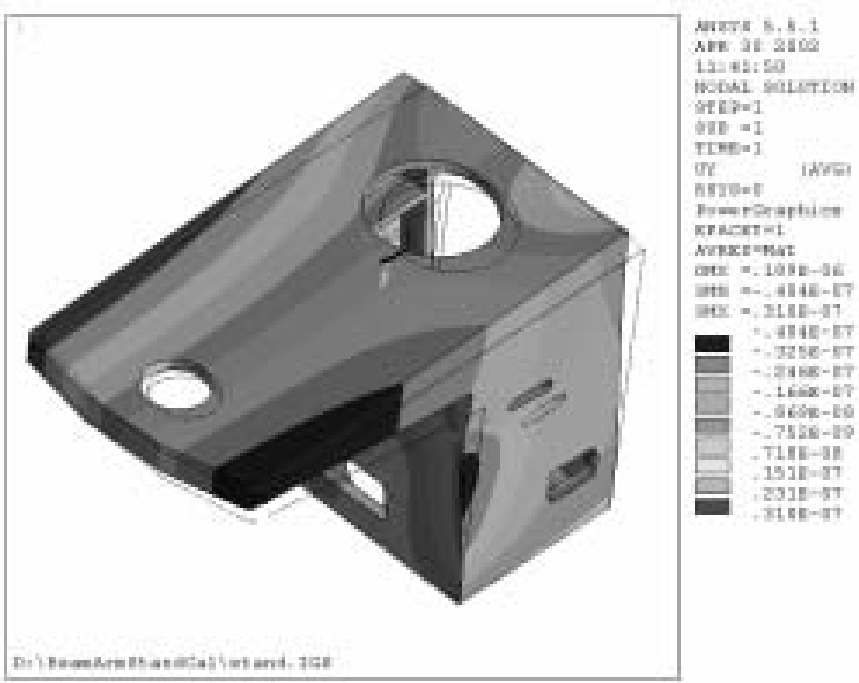

Fig. 19. Bond head stand displacement with $1 \mathrm{~N}$ exciting force at point A with small hammer.

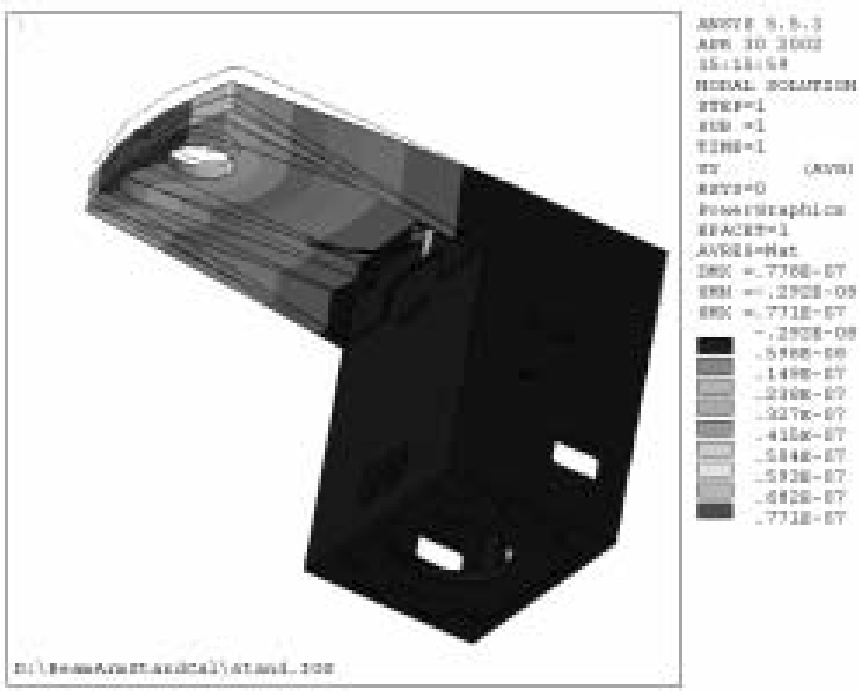

Fig. 20. Bond head stand displacement with $1 \mathrm{~N}$ exciting force at point $\mathrm{C}$ with big hammer.

Then measurement equipment needs to be selected according to the realistic condition. Displacement or acceleration sensors may be attached if the mass effect of the sensor is insignificant as compared to the structure, such as bond head stand. But for the bond arm, the weight of the arm is about 10 grams and a small accelerometer (for example, $P C B 333 B 42$ ) weighs about 4 grams. In that case, the mass effect cannot be ignored when the sensor is attached to the bond arm. Then a non-contact sensor, such as laser vibrometer, could be considered.

Finally, based on the measured results, the maximum displacements and resonance frequencies excited under operating conditions are of major concern. They are used to check whether the particle damping would be effective or not for the structure. To illustrate the concept, the measured results of the bond head stand under bonding process are used as an example. The largest vibration displacement of the bond head stand under the bonding process is shown in Fig. 23 where the biggest displacement is $49.1 \mu \mathrm{m}$. Since the error caused by the environmental vibration is about $7 \sim 9 \mu \mathrm{m}$, the actual displacement of the bond head stand could be about $40 \mu \mathrm{m}$. From the acceleration response measurement under the bonding process, as shown in Fig. 24, $245 \mathrm{~Hz}$ is a frequency of interest. Thus the 


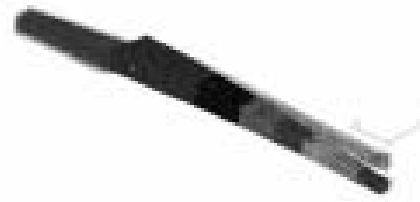

$1^{\text {st }}$ mode $(451.76 \mathrm{~Hz})$

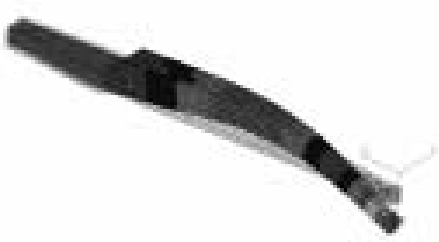

$3^{\text {rd }}$ mode $(1960.6 \mathrm{~Hz})$

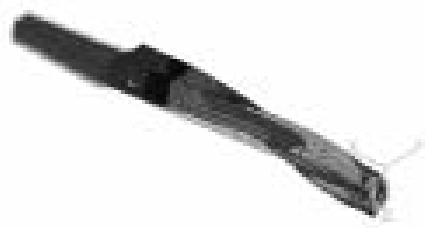

$5^{\text {th }}$ mode $(3192.3 \mathrm{~Hz})$

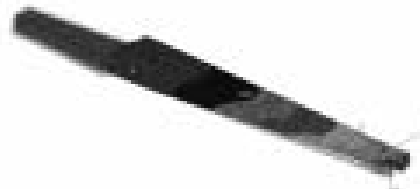

$2^{\text {nd }}$ mode $(861.02 \mathrm{~Hz})$

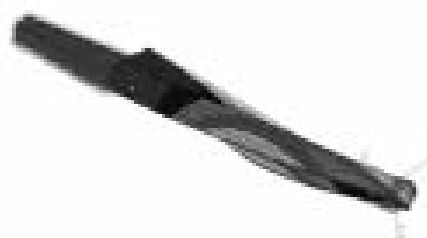

$4^{\text {th }}$ mode $(2053.8 \mathrm{~Hz})$

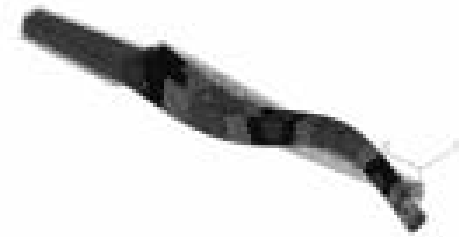

$6^{\text {th }}$ mode $(4831.5 \mathrm{~Hz})$

Fig. 21. The first six mode shapes of the bond arm.

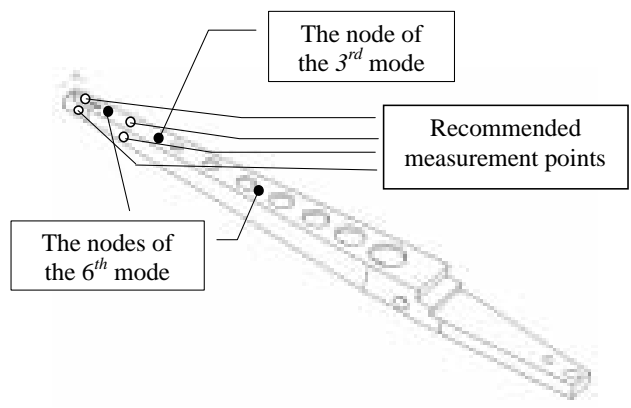

Fig. 22. Measurement points on the bond arm.

calculated acceleration at $245 \mathrm{~Hz}$ is $2.401 \mathrm{~m} / \mathrm{s}^{2}$, which is smaller than the critical value, $3.5 \mathrm{~m} / \mathrm{s}^{2}$. Therefore, it can be predicted that the particle damping would be ineffective for the bond head stand under such operating condition. In addition, it means that the vibration at other resonance frequencies smaller than $245 \mathrm{~Hz}$ could not be effectively suppressed either. It is found that the analysis results are consistent with the testing results. For the bond head stand under such operating condition, other methods for suppressing vibration should be considered.

\section{Step 3: Confirming the particle locations on the structure}

Based on information for the mode shapes in step 1 and the frequencies of interest in step 2, the locations for applying particles can be confirmed. To find suitable places for putting particles, the basic principle is that particles should be located in the wave crest of the mode shape of the frequency of interest. For example, if the 6th resonance frequency is concerned, the recommended places for adding particles are shown in Fig. 25. Perhaps, several resonance frequencies need to be considered simultaneously, the places to have particles should be considered according to the mode shapes and the amplitudes of all the concerned frequencies under the operating conditions. In general, the frequency with the largest amplitude should be firstly considered. If vibration transmits from one 


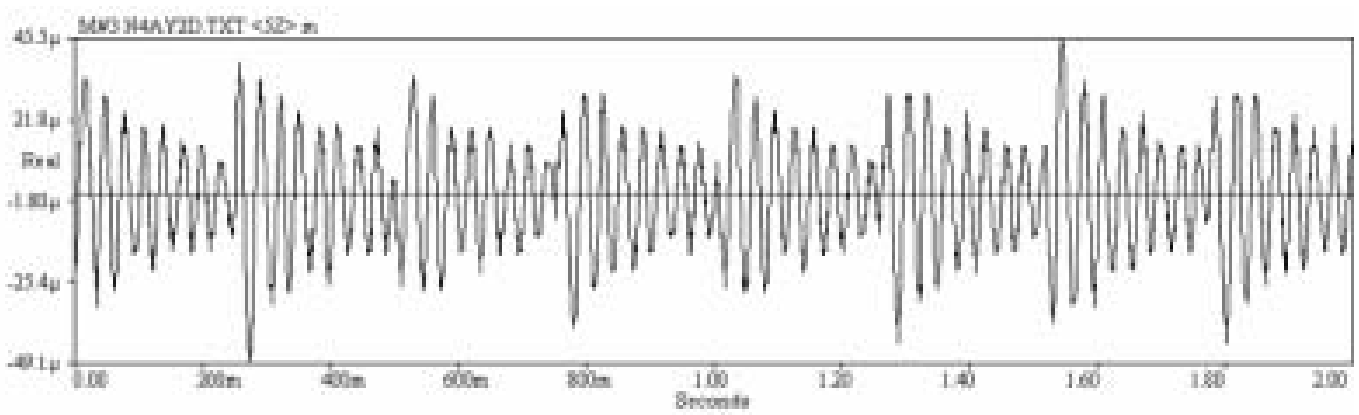

Fig. 23. Displacement vibration under y-excitation of motion stage.

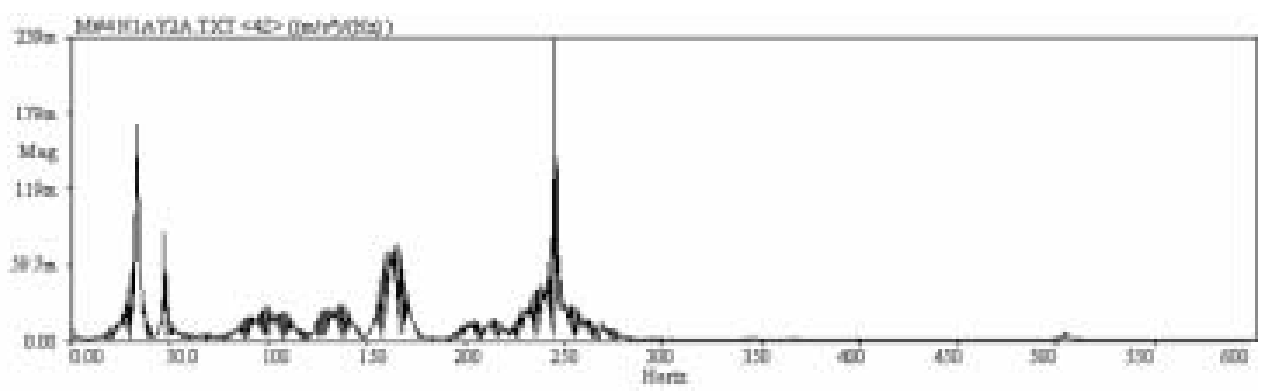

Fig. 24. Acceleration response of a measurement point under bonding process.

Table 7

Recommended particle diameters for the bond arm

\begin{tabular}{ccc}
\hline Mode No & FEM Analysis Frequency $(\mathrm{Hz})$ & Recommended particle diameter $(\mathrm{mm})$ \\
\hline 1 & 451.76 & 0.47 \\
2 & 861.02 & 0.51 \\
3 & 1960.6 & 0.61 \\
4 & 2053.8 & 0.62 \\
5 & 3192.3 & 1.00 \\
\hline
\end{tabular}

structure to another, particles can also be arranged on the transmitted path. This would reduce the vibration of the structure being transmitted.

\section{Step 4: Deciding particle parameter and hole size}

Particle density is a factor that can affect vibration suppression ability. Based on the experiments and experiences, the higher the particle density is, the better the vibration suppression ability is. Since tungsten has high density with $19.3 \times 10^{3} \mathrm{~kg} / \mathrm{m}^{3}$ compared to other common metals, it has been selected as the particle material in the experiments.

The particle diameter can be initially obtained from Fig. 27 based on the frequency of interest. The recommended particle diameters for the bond arm based on the resonance frequencies are shown in Table 7. In many cases, several resonance frequencies are concerned, and then several particle diameters are recommended. If possible, particles with different diameters could be placed at the best places obtained in step 3, for the purpose of the best vibration suppression. However, due to the availability of particles or other reasons, particles may not be exactly chosen according to the above decision. Then, all the recommended diameters could be averaged and particles are selected with the available size close to the average diameter as a compromise.

The hole diameter for particles must be fitted for the particle diameter. The recommended ratio of diameter between the particle and hole is in the range of $1 / 5 \sim 1 / 10$. The actual size of the hole could be changed beyond the suggested range due to the constraint of real structure.

Step 5: Stress analysis of drilled structure 
Table 8

Recommended packing ratios for the bond arm

\begin{tabular}{lcc}
\hline Mode No & FEM Analysis Frequency $(\mathrm{Hz})$ & Recommended packing ratio \\
\hline 1 & 451.76 & $69 \%$ \\
2 & 861.02 & $81 \%$ \\
3 & 1960.6 & $97 \%$ \\
4 & 2053.8 & $99 \%$ \\
5 & 3192.3 & $98 \%$ \\
\hline
\end{tabular}

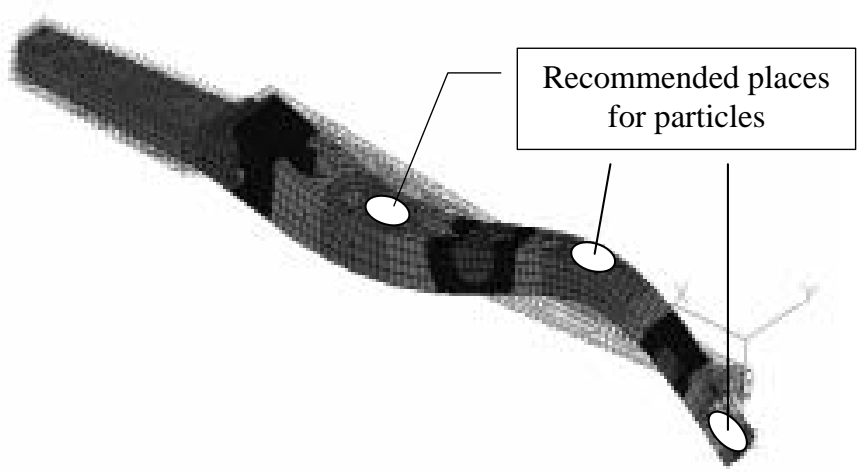

Fig. 25. Recommended locations for particles on the bond arm.

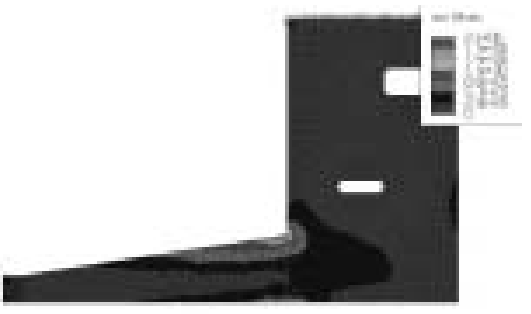

(a) XY surface

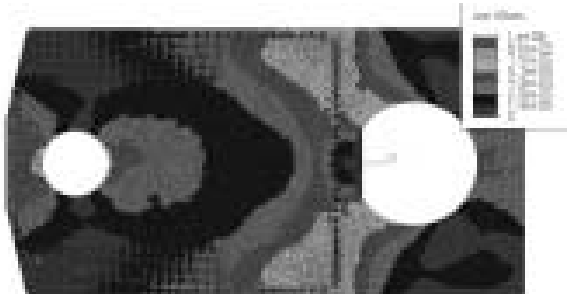

(b) XZ surface

Fig. 26. Strress distribution of bond head stand with holes.

Holes for particles are drilled in a structure and the strength of the structure may be affected by the drilled holes. In order to avoid destructing the structure, stress analysis should be carried on to check the possibility of stress concentration due to those drilled holes. The stress analysis for the bond head stand without and with drilled holes are briefly described here.

The bottom area of the bond head stand is applied fixed boundary condition in the FEA. A surface pressure of $5000 \mathrm{~N} / \mathrm{m}^{2}$ is applied on the top surface of $X Z$. Figure 26 shows Von Mises stress contours of the bond head stand with holes on the $X Y$ and $X Z$ surfaces. From the stress distribution contours on the $X Y$ surface, the maximum stress of the whole structure appears at the joint region between the beam part and stand part of the bond head stand, the maximum stresses are $2.158 \mathrm{E}+6$ and $2.275 \mathrm{E}+6 \mathrm{~Pa}$ for the bond head stand without and with holes respectively. From the stress contours on the $X Z$ surface, it can be seen that stress concentration appears near the drilled wholes, the maximum stresses on the $X Z$ surface are $8.144 \mathrm{E}+05$ and $1.219 \mathrm{E}+6 \mathrm{~Pa}$ for the stand without and with holes. According to the stress contours on different surfaces, it can be concluded that, after the holes being drilled in the bond head stand, the overall mechanical strength does not change much. Near the holes drilled in the $Y$ direction, there is more significant stress concentration. The increment percentage is about 50\%. However, the holes drilled in the $Z$ direction on the $X Y$ surface do not cause much stress increase under the applied load. The maximum stress caused by drilling holes, is far below the maximum stress of the whole structure. 


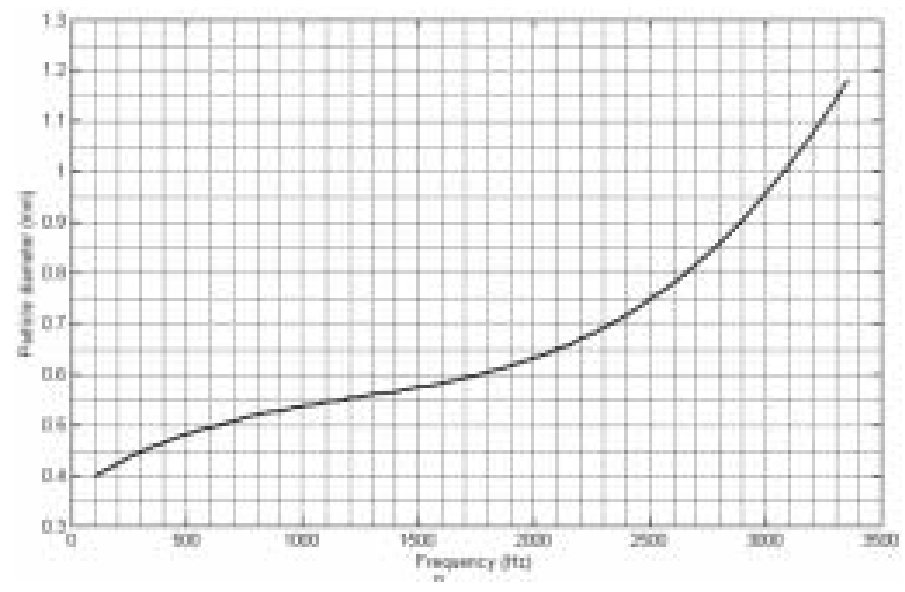

Fig. 27. The relationship between particle diameter and frequency.

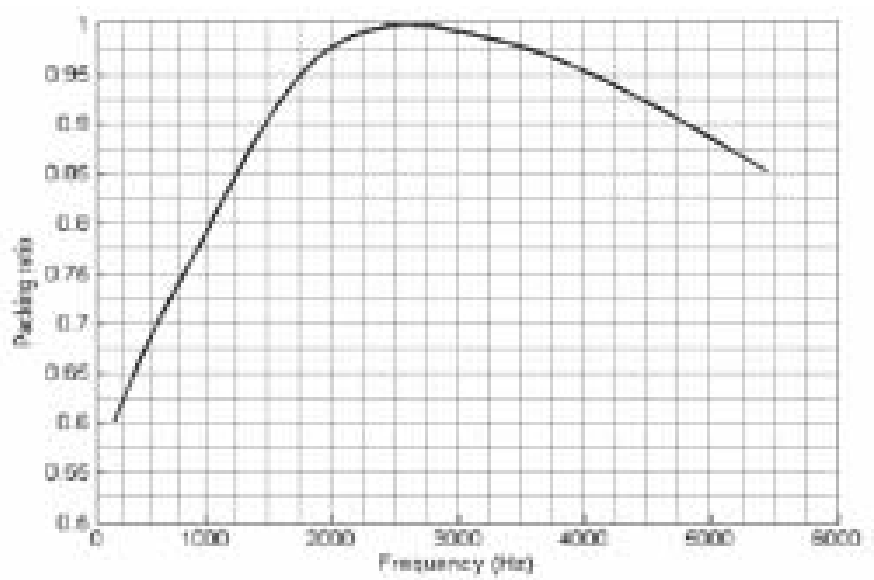

Fig. 28. The relationship between packing ratio and frequency.

Step 6: Deciding packing ratio of particles

Finally, the packing ratio of particles needs to be decided. The relationship between frequency and packing ratio obtained in Section 3 is shown in Fig. 28. The packing ratio can then be decided from Fig. 28 for the frequency of interest. For example, the packing ratios of particles for the bond arm are given in Table 8 .

Through the above six steps, particles can be applied to the structure if it is verified to be effective for suppressing structural vibration. The proposed guidelines may not lead to the optimal performance, but it should be a better one as the rule of thumb. If more experiments for boarder and finer range of particle parameters were performed, more accurate results would be obtained.

\section{Conclusion}

In this paper, extensive experimental data for beam, bond arm and bond head stand have been analyzed. Based on the experimental results and analyses, an empirical method is developed and design procedures for implementing particle damping are proposed. The framework presented in this paper would be valuable to decide whether the particle damping is effective and how to determine parameters of particles for a specific structure in order to obtain significant damping while applying the particle damping technology for practical applications. 


\section{Acknowledgements}

The work described in this paper was supported by a grant from Innovation and Technology Commission of Hong Kong Special Administrative Region, China and ASM Assembly Automation, Inc. (Project No. UIM/16).

\section{References}

[1] N. Popplewell and S.E. Semergicil, Performance of bean bag impact damper for a sinusoidal external force, J. of Sound and Vibration 133(2) (1989), 193-223.

[2] H.V. Panossian, Structural damping enhancement via non-obstructive particle damping technique, ASME J. of Vibration and Acoustics $\mathbf{1 1 4}$ (1992), 101-105.

[3] R. Sommer, Sports equipment for ball games having an improved attenuation of oscillation and kick-back pulses and an increased striking force, US Patent Number 5,454,562, Oct. 3, 1995.

[4] J.J. Moore, A.B. Palazzolo, R. Gadangi, T.A. Nale, S.A. Klusman, G.V. Brown and A.F. Kascak, A forced response analysis and application of impact dampers to rotordynamic vibration suppression in a cryogenic environment, ASME J. of Vibration and Acoustics 117 (1995), 300-310.

[5] R.D. Friend and V.K. Kinra, Particle impact damping, J. of Sound and Vibration 233(1) (2000), 93-118.

[6] B.L. Fowler, E.M. Flint and S.E. Olson, Effectiveness and predictability of particle damping, Proceedings of SPIE Conference on Smart Structures and Materials: Damping and Isolation, SPIE 3989 (2000), 356-367.

[7] M. Saeki, Impact damping with granular materials in a horizontally vibrating system, J. of Sound and Vibration 251(1) (2002), 153-161. 

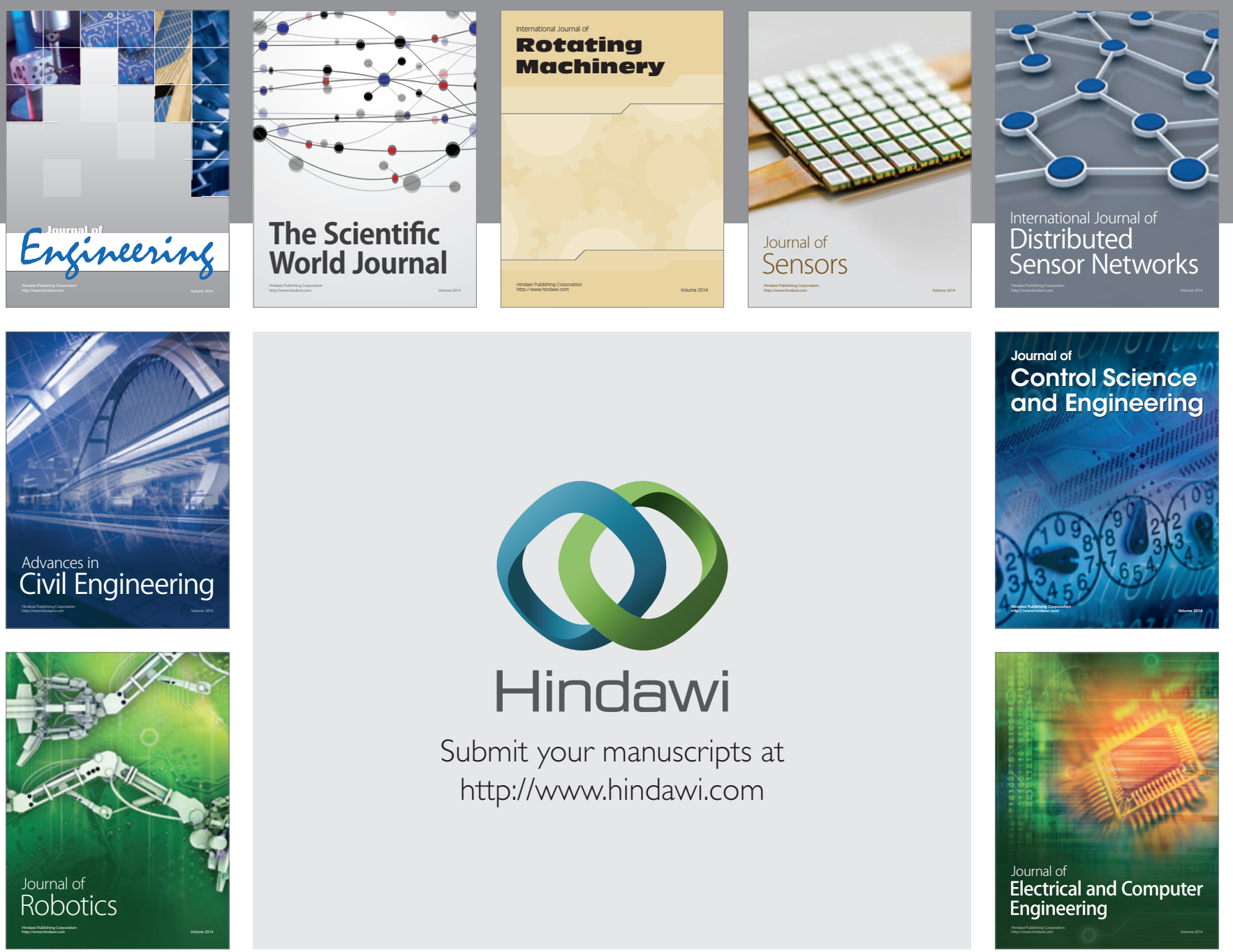

Submit your manuscripts at

http://www.hindawi.com
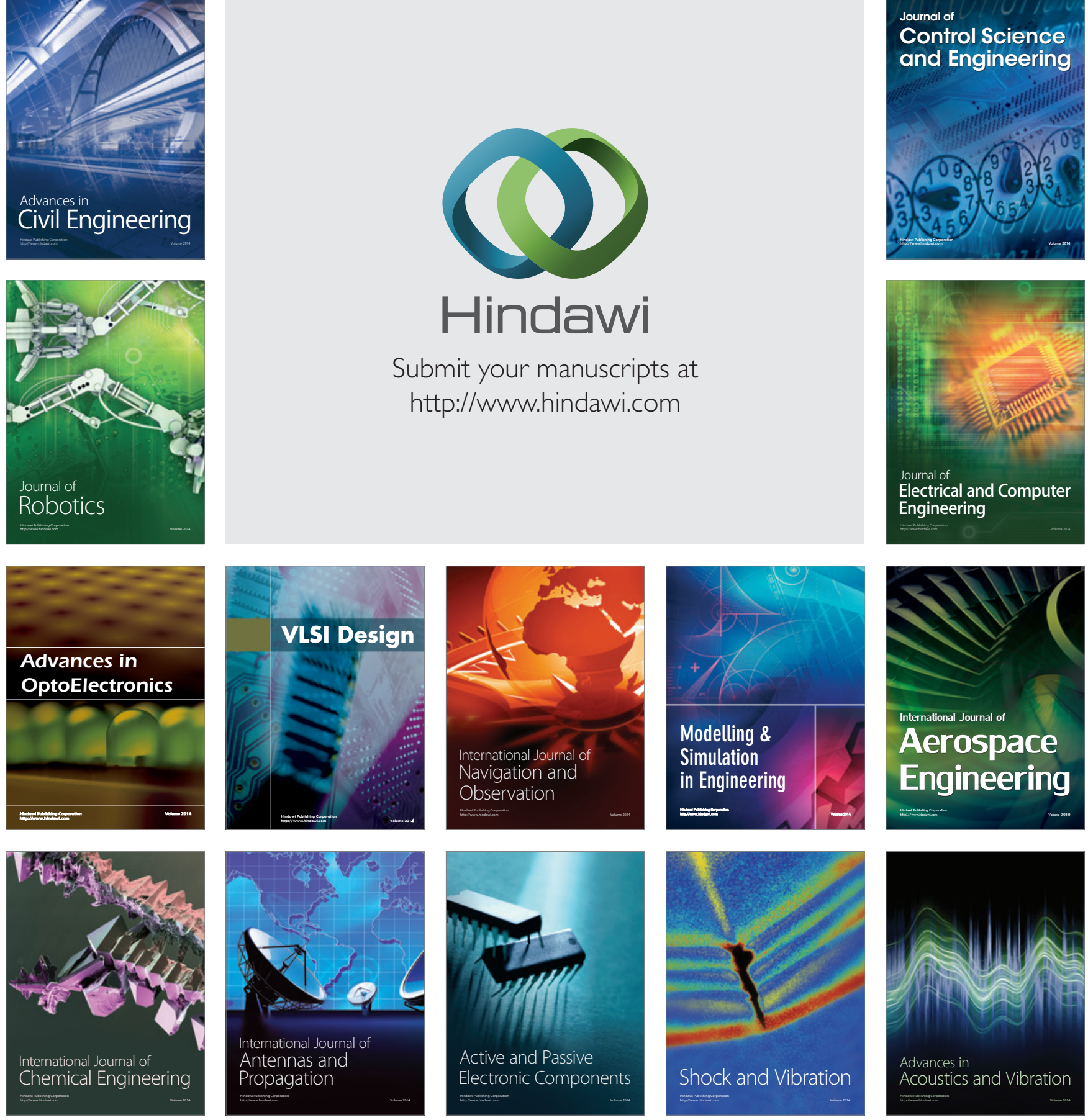